1. Zafiracopoulos, P. Breast cancer at the site of implantation of pacemaker generator. Lancet 1974, 1: 1174.

2. Magilian, D.J. \& Isshak, G. Carcinoma of the breast in a pacemaker pocket - simple recurrence or oncotaxis? $P A C E$ 1980, 3: $220-223$.

3. Rasmussen, K., Grimsgaard, C. Vik-mo, H. et al. Male breast cancer from pacemaker pocket. PACE 1985, 8: 761-763.
4. Hamaker, W.R. \& Lindell, M.E. Plasmacytoma arising in a pacemaker pocket. Ann Thorac Surg 1976, 21: 354-356.

5. Der Hagopian, R.P., Sugarbaker, E.V. \& Ketcham, A. Inflammatory oncotaxis. $J A M A$ 1978, 240: 374-375.

\title{
First use of G-CSF in chlorpromazine-induced agranulocytosis: a report of two cases
}

\author{
J.R. Kendra, F.P. Rugman', T.A. Flaherty' ${ }^{1}$, A. Myers², N. Horsfield², \\ A. Barton ${ }^{2}$ and L. Russell ${ }^{3}$
}

Burnley General Hospital, Burnley, ${ }^{1}$ Preston Royal Infirmary, Preston, ${ }^{2}$ Blackburn Royal Infirmary, Blackburn and ${ }^{3}$ Amgen (UK) Limited, 240 Cambridge Science Park, Milton Road, Cambridge CB4 4WD, UK

\begin{abstract}
Summary: Chlorpromazine-induced agranulocytosis is an uncommon disorder associated with a high frequency of fatality. We describe two patients with chlorpromazine-induced granulocytosis in whom granulocyte colony stimulating factor (G-CSF) administration enhanced the speed of neutrophil recovery. No toxicity was noted with G-CSF and both patients made a successful recovery. We propose there is a role for such cytokine therapy in patients with life-threatening agranulocytosis in order to speed the recovery of neutrophils.
\end{abstract}

\section{Introduction}

Idiosyncratic non-cytotoxic drug-induced agranulocytosis is an unpredictable adverse reaction to a variety of drugs in hypersensitive individuals. Chlorpromazine-induced agranulocytosis is associated with a reported $50 \%$ mortality rate. ${ }^{1}$ The period of agranulocytosis may be extensive and during this period the patient is at considerable risk of developing serious infections requiring prolonged hospitalization. ${ }^{2}$

Neutrophil production is under the control of several glycoproteins including granulocyte colony stimulating factor (G-CSF). Clinical trials have demonstrated that treatment with G-CSF reduces the duration and incidence of agranulocytosis with fever in patients who have received cytotoxic chemotherapy. ${ }^{3}$ Furthermore the use of G-CSF is a proven benefit in the treatment of congenital or

Correspondence: J.R. Kendra, F.R.C.Path., Burnley Health Care NHS Trust, Burnley General Hospital, Casterton Avenue, Burnley, Lancs BB10 2PQ, UK. Accepted: 14 April 1993 cyclic agranulocytosis and neutrophils obtained from individuals treated with G-CSF function normally in vitro and in vivo. ${ }^{4,5}$

We report two cases of chlorpromazine-induced agranulocytosis which were reversed following therapy with G-CSF.

\section{Case reports}

Case 1

A 35 year old female with a long history of depressive illness was admitted 3 weeks after commencing chlorpromazine $40 \mathrm{mg}$ daily and procyclidine $5 \mathrm{mg}$ daily with a fever of $39^{\circ} \mathrm{C}$ associated with a sore throat.

Physical examination revealed aphthous ulceration of the buccal mucosa and an inflamed throat. A blood count showed a haemoglobin of $10.4 \mathrm{~g} / \mathrm{dl}$, a platelet count of $204 \times 10^{9} / 1$ and a white blood count of $0.3 \times 10^{9} / 1$. On the blood film only lymphocytes were detected. A bone marrow aspirate 
revealed increased proerythroblasts but a reduction of intermediate and late normoblasts, normal megakaryocytes and lymphocyte numbers and no detectable granulopoiesis.

Chlorpromazine therapy was discontinued and the patient was treated with intravenous piperacillin, gentamicin and oral fluconazole in isolation facilities. Two days following admission, therapy with G-CSF $300 \mu \mathrm{g}$, given subcutaneously, with a 24 hour interval between doses was commenced.

The patient became apyrexial after 48 hours but remained severely neutropaenic with an absolute neutrophil count of $0.2 \times 10^{9} / 1$ on day 4 . By day 8 of G-CSF therapy the white cell count rose to $3.2 \times 10^{9} / 1$ with an absolute neutrophil count of $1.5 \times 10^{9} / 1$. G-CSF was continued for a further 48 hours. Following this the white cell count continued to rise, peaking at $44 \times 10^{9} / 1$ with $66 \%$ neutrophils $31 \%$ metamyelocytes and then gradually fell over the subsequent 4 days to a baseline of $16.3 \times 10^{9} / 1$. The platelet count also rose following treatment to a peak level of $704 \times 10^{9} / 1$ on the eighth day of treatment with G-CSF. The haemoglobin dropped to $9.7 \mathrm{~g} / \mathrm{dl}$ and a transfusion with 2 units of red cell concentrates was administered. The haemoglobin was subsequently maintained within normal limits without further transfusion.

The patient was discharged 6 days after discontinuing G-CSF but was readmitted 24 hours later with a perianal abscess which required surgical incision, drainage and opening of a fistula in ano. Following surgery the patient made a good postoperative recovery requiring no antibiotic therapy and was discharged home.

\section{Case 2}

A 53 year old female with a longstanding history of manic depression was admitted when a routine full blood count demonstrated a leucopaenia with a total white cell count of $1.9 \times 10^{9} / 1$ with absent neutrophils. She complained of a productive cough and a dry throat but no other symptoms of note. She was on long standing lithium therapy and took ibuprofen intermittently. She had just completed a 3 week course of chlorpromazine $100 \mathrm{mg}$ daily and 24 hours prior to admission had been commenced on zuclopenthixol. A full blood count taken 3 weeks prior to admission had been reported as normal. A bone marrow aspirate revealed complete absence of myeloid maturation but normal erythropoeisis and megakaryopoeisis.

\section{References}

1. Medicines Control Agency (UK). Adverse Drug Reactions 1963-1992.

2. Vincent, P.C. Drug-induced aplastic anaemia and agranulocytosis: incidence and mechanisms. Drugs 1986, 31: $52-63$.
Following admission she became pyrexial and was commenced on broad-spectrum antibiotics in the form of piperacillin and gentamicin. G-CSF was commenced at a dose of $350 \mu \mathrm{g}$ daily given subcutaneously. After 3 days of treatment a neutrophil response was noted and by day 4 of treatment her absolute neutrophil count had risen to $0.5 \times 10^{9} / 1$. By day 5 her full blood count had recovered with a haemoglobin of $11.4 \mathrm{~g} / \mathrm{dl}$, white cell count $5.4 \times 10^{9} / 1$ with $40 \%$ neutrophils and a platelet count of $223 \times 10^{9} / 1$. Her pyrexia resolved and she was discharged home once treatment with G-CSF had been discontinued for 2 days. Her chlorpromazine has been discontinued and she remains on lithium therapy.

\section{Discussion}

Despite improved supportive care drug-induced agranulocytosis is still associated with significant mortality ${ }^{1,2}$ and in severe cases spontaneous neutrophil recovery following drug withdrawal can take up to 14 days. ${ }^{3}$ The successful use of G-CSF in the management of neutropaenia after chemotherapy and in the treatment of severe congenital or cyclic neutropaenia is now leading to its use in the management of drug-induced agranulocytosis. To date there have been several reports of clozapine induced agranulocytosis successfully treated with G-CSF ${ }^{6,7} \mathrm{~A}$ further case report has demonstrate the benefits of G-CSF in the treatment of druginduced agranulocytosis from a variety of agents.

These cases again highlight the benefits of G-CSF in the treatment of drug-induced agranulocytosis due, on these occasions, to chlorpromazine In the first case it is also interesting to speculate whether the perianal abscess would have been life threatening had there not been such rapid neutrophil recovery following G-CSF therapy. Alternatively, it could be argued that it only became apparent once there was an adequate neutrophil count to mount a response. However, it is fair to say that its treatment was made substantially easier and without further complications as a result of an adequate neutrophil count and could have been life threatening had there been persistent neutropaenia.

In view of these cases and the others in the literature we would propose that G-CSF is used in the treatment of drug-induced agranulocytosis to improve the outcome of this potentially lethal condition.

3. Crawford, J., Ozer, H., Stoller, R. et al. Reduction by granulocyte colony stimulating factor of fever and neutropenia induced by chemotherapy in patients with small cell lung cancer. N Engl J Med 1991, 325: 164-170. 
4. Bonilla, M.A., Gillo, A.P., Ruffeiro, M. et al. Effects of recombinant human granulocyte colony stimulating factor on neutropaenia in patients with congenital agranulocytosis. $N$ Engl J Med 1989, 320: 1574-1580.

5. Bronchud, M.D., Potter, M.R., Morgenstern, G. et al. In vitro and in vivo analysis of the effects of recombinant human granulocyte colony stimulating factor in patients. $\mathrm{Br} \mathrm{J}$ Cancer 1988, 58: 64-69.

6. Gerson, S.L., Gullion, G., Yeh, H.S. \& Masor, C. Granulocyte colony-stimulating factor for clozapine induced agranulocytosis. Lancet 1992, 340: 1097.
7. Weide, R., Koppler, H., Heymanns, J., Pfluger, K.H. \& Havemann, K. Successful treatment of clozapine induced agranulocytosis with G-CSF. Br J Haematol 1992, 80: 557-559.

8. Patton, W.N., Holyoake, T.L., Yates, J.M., Boughton, B.J. \& Franklin, I.M. Accelerated recovery from drug induced agranulocytosis following G-CSF therapy. Br J Haematol 1992, 80: 564-565.

\title{
Type IV renal tubular acidosis and spironolactone therapy in the elderly
}

\author{
J.E. O'Connell* and N.R. Colledge
}

Geriatric Medicine Unit, University of Edinburgh, City Hospital, Greenbank Drive, Edinburgh EH10 5SB, UK

\begin{abstract}
Summary: Spironolactone therapy is a well-known cause of hyperkalaemia, but in susceptible patient, it may also be associated with metabolic acidosis. We report a case of severe renal tubular acidosis (Type IV) with life-threatening hyperkalaemia caused by spironolactone, and discuss the mechanisms by which this may occur.
\end{abstract}

\section{Introduction}

Approximately one-fifth of people aged over 65 years take some form of diuretic. ${ }^{1}$ In order to prevent associated hypokalaemia it is common practice to co-prescribe potassium supplements or to use a potassium-sparing diuretic. It is well known that the latter should be avoided in renal failure, but the risk of significant hyperkalaemia in elderly subjects with mild renal impairment is less well recognized. ${ }^{2}$ We describe the case of an 88 year old woman who developed life-threatening hyperkalaemia with distal renal tubular acidosis (type IV) while on treatment with spironolactone.

\section{Case report}

An 88 year old woman was admitted to hospital with fluctuating confusion, slurred speech and inability to weight bear of sudden onset. She had a past history of hypertension, congestive cardiac

Correspondence: N.R. Colledge, B.Sc., M.R.C.P. *Present address: Dryburn Hospital, Durham, UK. Accepted: 1 April 1993 failure, bilateral lower leg ulceration, hyperuricaemia and poor mobility due to osteoarthritis. Her daily medication included spironolactone $200 \mathrm{mg}$, frusemide $80 \mathrm{mg}$, allopurinol $100 \mathrm{mg}$, quinine sulphate $300 \mathrm{mg}$ and co-codamol (paracetamol and codeine) as required for pain.

Physical examination revealed a mentally alert, obese lady with a pulse of 88 beats/minute and a blood pressure of $170 / 90 \mathrm{mmHg}$. There was no postural drop in blood pressure. Skin turgor was reduced and the jugular venous pulse could not be demonstrated, although there was a trace of ankle oedema. Auscultation of her chest revealed bilateral basal inspiratory crepitations. She had a mild right hemiparesis, and a right VII nerve palsy of upper motor neurone type with associated dysarthria.

Serum biochemistry on admission showed urea $27.2 \mathrm{mmol} / 1$ (normal range $2.5-6.6 \mathrm{mmol} / \mathrm{l}$ ), creatinine $235 \mu \mathrm{mol} / \mathrm{l}$ (normal range 55-150 $\mu \mathrm{mol} / \mathrm{l}$ ), sodium $129 \mathrm{mmol} / \mathrm{l}$ (normal range 132 $144 \mathrm{mmol} / \mathrm{l}$ ) and potassium $7.6 \mathrm{mmol} / 1$ (normal range 3.3-4.7 mmol/l). Arterial blood gas analysis revealed a metabolic acidosis (hydrogen ion $51 \mathrm{nmol} / 1$, normal range $34-44 \mathrm{nmol} / \mathrm{l}$; bicar- 